\title{
From Communication to Togetherness
}

\author{
Piet Kommers \\ University of Twente \\ The Netherlands
}

The web 2.0 offered a growing connectivity even before an explicit demand for dense interaction was felt. The current pushing role of social media clearly illustrates the desperate search for communicative and societal needs. Whereas communities demand togetherness, urban societies excel in the need for privacy, freedom and selectiveness. The virtue of ubiquitous 'presence' and virtual immersiveness nowadays shows a higher price than expected in the naieve era of early smart phones.

This lecture brings you a cross media tour to what we may expect to happen in post social media societies; fasten your seat belts. 